\title{
Association of TP53 gene codon 72 polymorphism with endometriosis in Mexican women
}

\author{
M.P. Gallegos-Arreola ${ }^{1}$, L.E. Figuera-Villanueva ${ }^{2}$, A.M. Puebla-Pérez ${ }^{3}$, \\ H. Montoya-Fuentes ${ }^{1}$, A.E. Suarez-Rincon ${ }^{4}$ and G.M. Zúñiga-González ${ }^{1}$ \\ ${ }^{1}$ Molecular Medicine Department, Biomedical Research Center West, \\ Instituto Mexicano del Seguro Social, Guadalajara, México \\ ${ }^{2}$ Genetics Department, Biomedical Research Center West, \\ Instituto Mexicano del Seguro Social, Guadalajara, México \\ ${ }^{3}$ Laboratory of Immunopharmacology, CUCEI, \\ Universidad de Guadalajara, Guadalajara, México \\ ${ }^{4}$ UMAE, Hospital General Regional 45, \\ Instituto Mexicano del Seguro Social, Guadalajara, México \\ Corresponding author: M.P. Gallegos-Arreola \\ E-mail: patrici0803@yahoo.com.mx
}

Genet. Mol. Res. 11 (2) 1401-1408 (2012)

Received September 28, 2011

Accepted February 20, 2012

Published May 15, 2012

DOI http://dx.doi.org/10.4238/2012.May.15.10

\begin{abstract}
The TP53 tumor suppressor gene plays an important role in cell cycle regulation; polymorphisms of this gene have been associated with endometriosis. We examined the role of TP53 codon 72 polymorphism by comparing genotypes of 235 healthy Mexican women (controls with surgically excluded endometriosis) with the genotypes of 151 Mexican women with endometriosis. The observed genotype frequencies for controls and endometriosis patients were 8 and 22\% for proline/proline (Pro/Pro), 30 and 34\% for proline/arginine (Pro/Arg), and 62 and 44\% for arginine/arginine (Arg/Arg), respectively. We found that odds ratio $(\mathrm{OR})=3.3 ; 95 \%$ confidence intervals $(95 \% \mathrm{CI})=1.7-6.4 ; \mathrm{P}=0.0001$. The association was also evident in the comparison of the distributions of genotypes Pro/Pro and Pro/Arg in patients with moderate-to-severe endometriosis; $\mathrm{OR}=1.9 ; 95 \% \mathrm{CI}=0.95-3.9 ; \mathrm{P}=0.049$. We suggest
\end{abstract}


that genotype Pro/Pro of codon 72 polymorphism in TP53 contributes significantly to endometriosis susceptibility in the Mexican population.

Key words: TP53 gene; Polymorphism; Codon 72; Mexican population; Endometriosis

\section{INTRODUCTION}

The presence of endometrial glands and stroma outside of the uterine cavity is called endometriosis. The endometrial tissue retains its function even when it is present outside the uterus (Dunselman, 2002). Endometriosis causes functional impairment and infertility in 10$15 \%$ of women of reproductive age (Sunderam et al., 2009), and its incidence varies depending on population studies and diagnostic methods because endometriosis is only diagnosed by laparoscopy or during an unrelated surgical procedure (Troyer, 2007). In Mexico and in many countries across the world, the incidence of endometriosis has increased during the last 10 years, and it is now one of the leading causes of infertility in women of reproductive age (unpublished data).

Since endometriosis is considered to be a multifactorial disease and its incidence varies, there is a need for continued research to identify polymorphisms that are associated with the occurrence of endometriosis and its varying clinical stages. Endometriosis might result from a combination of abnormal protein interactions and environmental factors (Giudice and Kao, 2004). The TP53 tumor suppressor gene is located on chromosome 17 and encodes the nuclear phosphoprotein p53 (Kern et al., 1991). This protein participates in cell cycle regulation, apoptosis, DNA repair, and angiogenesis and is mutated in more than $50 \%$ of all cancers (Thomas et al., 1999). The TP53 gene consists of 11 exons and 10 introns and has a high frequency of mutations and polymorphisms (Kern et al., 1991). Although it is unclear which TP53 gene polymorphism is responsible for alterations in $\mathrm{p} 53$ protein activity, several studies have shown that polymorphisms in intron 3 and exon 4 are involved in the development of various pathologies (Thomas et al., 1999). Thomas et al. (1999) showed that structural changes in the p53 protein can result from a single amino acid change that causes irregular protein activity and loss of function due to an inability to interact with other transcription factors for transcription. These alterations can lead to carcinogenesis and tumor formation. The codon 72 polymorphism is located in a SH3-binding domain site, which is required for growth suppression and apoptosis mediated by p53 but not for cell cycle arrest (Thomas et al., 1999). The proteins p53Arg72 and p53Pro72 have different biochemical and biological properties such as difference in the binding to components of the transcriptional machinery and difference in the activation of transcription (Doosti et al., 2011). The p53Arg72 protein induces apoptosis faster and suppresses transformation more efficiently than the p53Pro72 protein (Doosti et al., 2011). Evidence of an association between a polymorphism in codon 72 of the TP53 gene and endometriosis was described by Hsieh and Lin (2006) who reported a high frequency (30.7\%) of the Arg genotype in endometriosis patients. Ammendola et al. (2008) studied the interaction between TP53 and PTPN22 and found that the Arg genotype showed a protective effect against endometriosis in carriers of the T allele of PTPN22. Chang et al. (2002) and Goodman et al. (2009) showed an association between the Pro/Pro and heterozygote genotypes of the TP53 gene and endometriosis. Ghasemi et al. (2010), showed an increased frequency of 
the Pro allele in Iranian women with endometrial cancer. The frequency of the TP53 gene codon 72 polymorphism has been shown to vary across diverse ethnic groups. In Swedish Saamis, Swedish, Chinese (Själander et al., 1996), Italian, Mexican, Venezuelan, Brazilian, Colombian, and Peruvian populations (Suárez-Rincon et al., 2002; Chiurillo et al., 2010), the frequencies range between 4 and 12\%. However, in Indians, African Blacks (Själander et al., 1996), Japanese, Ugandan, Nigerian, and South Africans, the frequencies range between 15 and $47 \%$ (Chiurillo et al., 2010). The aim of this study was to determine the possible association between the codon 72 polymorphism of the TP53 gene with an increased risk of endometriosis in Mexican women.

\section{MATERIAL AND METHODS}

DNA was extracted from the peripheral blood lymphocytes by using standard protocols (Miller et al., 1988). Blood samples were collected from 235 women without endometriosis, with an average age of 32 years. These women had undergone surgical procedures or diagnostic laparoscopy for various reasons such as polycystic ovary syndrome and/or infertility, but endometriosis had been ruled out as a potential diagnosis. They were not matched by age with the patient group. Blood was collected from 151 women from the metropolitan area of Guadalajara who had surgically and histologically diagnosed endometriosis. The patients were recruited between January 2002 and July 2010 and were classified as having minimal/ mild (Stage I-II) or moderate/severe (Stage III-IV) endometriosis, as per the American Fertility Society classification system. Appropriate written informed consent and approval from the ethics committee of the Institution were obtained. Efforts were made to exclude the siblings of the women who had already been sampled. Clinical (endometriosis stage) and demographical data (age, smoking status, and familial history) were obtained using questionnaires. Amplification of exon 4 of TP53 was performed using PCR with the following primers: 5'-TTGCCG TCCCAAGCAATGGATGA-3' and 5'-TCTGGGAAGGGACAGAAGATGAC-3' (Liu et al., 2001). Reactions were performed in a total PCR volume of $15 \mu \mathrm{L}$ containing $0.2 \mathrm{mM}$ dNTPs (Invitrogen, USA), 5 pmol primers, $2.5 \mathrm{mM} \mathrm{MgCl}_{2}, 1.5 \mathrm{U}$ Taq polymerase (Invitrogen, USA), and $0.8 \%$ bovine serum albumin (Promega, USA). PCR conditions were $94^{\circ} \mathrm{C}(4 \mathrm{~min})$, followed by 35 cycles of $94^{\circ} \mathrm{C}(30 \mathrm{~s}), 68^{\circ} \mathrm{C}(1 \mathrm{~min}), 72^{\circ} \mathrm{C}(1 \mathrm{~min})$, and final extension at $72^{\circ} \mathrm{C}(7$ min). The amplified products were digested with Bst UI restriction enzyme (Promega, USA) at $60^{\circ} \mathrm{C}$ for $12 \mathrm{~h}$. Allele discrimination was performed using $6 \%$ polyacrylamide gel (29:1) electrophoresis, followed by silver staining (Sanguinetti et al., 1994). The 199-bp fragment was found to indicate a polymorphic type genotype (proline). Two fragments of 113 and $86 \mathrm{bp}$ indicated the wild type genotype (arginine).

Allele frequencies were obtained by direct counting. The Hardy-Weinberg equilibrium was tested by chi square test to compare the observed genotype frequencies to the expected frequencies among control subjects. Odds ratios and 95\% confidence intervals (CI) were also calculated. A two-sided $\mathrm{P}<0.05$ was considered statistically significant. All statistical analyses were performed using PASW Statistic Base 18 software, 2009 (Chicago, IL).

\section{RESULTS}

Table 1 shows the comparative epidemiological data from endometriosis patients and 
controls. In the endometriosis group, the observed average age was 31.7 years, ranging from 13 to 62 years. In this group, 71\% (107/151) of the patients were less than 35 years old and $7 \%(10 / 151)$ had a positive family history of endometriosis. Stage II-IV endometriosis was the most frequent $(71 \%, 107 / 151)$, followed by stage I-III $(29 \%, 44 / 151)$.

\begin{tabular}{|c|c|c|c|}
\hline & Controls $(\mathrm{N}=235)$ & Endometriosis patients $(\mathrm{N}=151)$ & $P$ value \\
\hline \multicolumn{4}{|l|}{ Age (years) } \\
\hline Mean (SD) & $32.2(7.46)$ & $31.76(7.2)$ & $\mathrm{NS}^{2}$ \\
\hline$<35$ years $(\%)$ & $163(69)$ & $107(71)$ & \\
\hline$\geq 35$ years $(\%)$ & $72(31)$ & $44(29)$ & \\
\hline \multicolumn{4}{|l|}{ Family history, N (\%) } \\
\hline Yes, N (\%) & $1(0.4)$ & $10(7)$ & $\mathrm{P}<0.05^{1}$ \\
\hline No, $\mathrm{N}(\%)$ & $234(99.6)$ & $141(93)$ & \\
\hline \multicolumn{4}{|l|}{ Smoking status, N (\%) } \\
\hline Current smokers & $62(27)$ & $19(12)$ & $\mathrm{P}<0.05^{1}$ \\
\hline Smoking in the past & $21(9)$ & $13(9)$ & $\mathrm{NS}^{1}$ \\
\hline Non-smokers & $111(47)$ & $94(62)$ & $\mathrm{P}<0.05^{1}$ \\
\hline Passive smokers & $41(17)$ & $25(17)$ & $\mathrm{NS}^{1}$ \\
\hline \multicolumn{4}{|c|}{ Stage endometriosis, N (\%) } \\
\hline I & & $24(16)$ & \\
\hline II & & $40(27)$ & \\
\hline III & & $20(13)$ & \\
\hline IV & & $67(44)$ & \\
\hline
\end{tabular}

${ }^{1}$ Fisher exact test; ${ }^{2}$ Student $t$-test. SD $=$ standard deviation. Nonsignificant (NS).

Table 2 shows the genotypes and allele frequencies for the codon 72 TP53 polymorphism. The Pro/Pro genotype was observed in $8 \%(19 / 235)$ of the control group and $22 \%$ $(34 / 151)$ of the endometriosis patients; the difference was statistically significant $(\mathrm{OR}=3.3$; $95 \% \mathrm{CI}=1.7-6.4 ; \mathrm{P}=0.0001)$. All genotype distributions in the control group were in HardyWeinberg equilibrium.

Table 2. Genotype distribution of the codon 72 polymorphism in healthy controls and endometriosis patients.

\begin{tabular}{|c|c|c|c|c|c|c|}
\hline & \multicolumn{3}{|c|}{ Genotype } & \multicolumn{3}{|c|}{ Alleles } \\
\hline & $\operatorname{Arg} / \operatorname{Arg} N(\%)$ & Arg/Pro N (\%) & Pro/Pro N (\%) & Pro/Pro-Arg/Pro N (\%) & $\operatorname{Arg} 2 n(\%)$ & Pro $2 n(\%)$ \\
\hline Controls $(\mathrm{N}=235)$ & $145(62)$ & $71(30)$ & $19(8)$ & $90(38)$ & $361(77)$ & $109(23)$ \\
\hline Endometriosis patients $(\mathrm{N}=151)$ & $66(44)$ & $51(34)$ & $34(22)$ & $84(56)$ & $183(61)$ & $119(39)$ \\
\hline \multicolumn{7}{|l|}{ Controls $v_{s}$ endometriosis patients } \\
\hline OR & 0.48 & & 3.3 & 2.0 & 0.46 & 2.15 \\
\hline 95\%CI (low-high) & $(0.31-0.75)$ & & $(1.7-6.4)$ & $(1.3-3.2)$ & $(0.33-0.64)$ & $(1.55-2.99)$ \\
\hline$P$ value & 0.0007 & & 0.0001 & 0.0007 & 0.000002 & 0.000002 \\
\hline
\end{tabular}

$\mathrm{CI}=$ confidence interval.

Table 3 shows the frequency of the codon 72 TP53 polymorphism in endometriosis patients stratified according to stages I-II and III-IV. The differences in genotype Pro/Pro and heterozygosity between patients and controls was statistically significant with regard to stage III-IV $(\mathrm{OR}=1.9,95 \% \mathrm{CI}=0.95-3.9 ; \mathrm{P}=0.049)$ and genotype $\mathrm{Arg} / \mathrm{Arg}(\mathrm{OR}=0.5,95 \% \mathrm{CI}=$ $0.25-1.0 ; \mathrm{P}=0.0490)$. 
Table 3. Genotype distribution of the codon 72 of TP53 polymorphism in endometriosis patients with respect to endometriosis status.

\begin{tabular}{lcccr}
\hline & \multicolumn{2}{c}{ Endometriosis patients (N = 151) } & OR (CI95\% low-high) & P value \\
\cline { 2 - 4 } & $\operatorname{Arg} / \operatorname{Arg~N}(\%)$ & $\operatorname{Arg} /$ Pro and Pro/Pro N (\%) & & \\
\hline I-II & $33(53)$ & $29(47)$ & $0.5(0.25-1.0)$ & 0.049 \\
III-IV & $33(37)$ & $56(63)$ & $1.9(0.95-3.9)$ & 0.049 \\
\hline
\end{tabular}

$\mathrm{CI}=$ confidence interval.

A multivariate logistic regression analysis, in which the endometriosis group was classified as stage I-II and III-IV as the dependent variables, was carried out using the following independent variables: Arg/Arg, Arg/Pro, and Pro/Pro genotypes, and tobacco consumption. The endometriosis patients with stages III-IV carriers of heterozygous genotype of codon 72 polymorphism and passive smokers had a risk of $2.1(95 \% \mathrm{CI}=1.0-4.3)$ and $3.4(95 \% \mathrm{CI}=$ $1.1-9.8$ ), respectively (Table 4).

Table 4. Multivariate logistic regression analysis of the endometriosis I-II and III-IV groups.

\begin{tabular}{|c|c|c|c|c|c|c|c|c|}
\hline \multirow[b]{2}{*}{ Variable } & \multirow[t]{2}{*}{ Beta } & \multirow[t]{2}{*}{ SE } & \multirow[t]{2}{*}{ Wald } & \multirow[t]{2}{*}{ d.f. } & \multirow[t]{2}{*}{ Significance } & \multirow[t]{2}{*}{ OR } & \multicolumn{2}{|c|}{$95 \% \mathrm{CI}$} \\
\hline & & & & & & & Lower & Upper \\
\hline Arg/Pro & 0.74 & 0.37 & 3.94 & 1 & 0.047 & 2.1 & 1.0 & 4.3 \\
\hline Passive smokers & 1.2 & 0.53 & 5.2 & 1 & 0.022 & 3.4 & 1.1 & 9.8 \\
\hline
\end{tabular}

Variables in the equation: Arg/Arg, Arg/Pro, Pro/Pro, non-smokers, smoking in the past, current smokers, and passive smokers. d.f. $=$ degrees of freedom; $\mathrm{OR}=$ odds ratio; $95 \% \mathrm{CI}=$ confidence interval at $95 \%$.

\section{DISCUSSION}

In Mexico, the incidence of endometriosis has increased during the last 10 years. Technological advances in laparoscopic techniques have helped in understanding the endometriosis etiology. Endometriosis is one of the leading causes of infertility in women of reproductive age (Ayala and Mota, 2007). Our results showed that $71 \%$ of the patients were $<35$ years old, which is consistent with the findings of other international reports showing that the incidence of endometriosis is higher in women of reproductive age (Gylfason et al., 2010).

When the study groups were adjusted according to family history of endometriosis, $7 \%(10 / 151)$ of patients had a positive familial history of endometriosis (mother or sister). First-degree relatives of affected women have a risk of developing endometriosis between 5 and $8 \%$ (Nouri et al., 2010). Thus, our data are consistent with previously reported rates.

The association of endometriosis stage remains controversial. However, we observed that stage IV (severe) was most frequently observed (44\%), followed by stage II (mild; 27\%). This association is consistent with that reported by Gruppo Italiano per lo Studio dell'Endometriosi (2001).

The TP53 gene has been proposed as a candidate for studies on endometriosis with regard to susceptibility (Goodman et al., 2009; Ribeiro et al., 2009), infertility (Chang et al., 2002; Kang et al., 2009; Ghasemi et al., 2010), and the role of endometriosis as a neoplastic monoclonal disease and precursor to ovarian cancer (Mandai et al., 2009). Ghasemi et al. 
(2010) reported that Iranian women with the proline allele of TP53 codon 72 polymorphism had an increased risk of endometriosis cancer. Akahane et al. (2007) found mutations in the TP53 gene of 30.8\% (4/13) of endometrial tissues coexisting with ovarian clear cell carcinoma, and Kang et al. (2009) suggested that proline allele of codon 72 polymorphism of TP53 regulates the efficiency of human reproduction.

Genetic and environmental factors play an important role in endometriosis susceptibility. Kobayashi et al. (2009) proposed that pro-oxidant factors in retrograde menstruation or ovarian hemorrhage can stimulate loss of heterozygosity and DNA damage and are critical precursors to carcinogenesis.

Several histopathological studies indicate that endometriosis might be the neoplastic process leading to endometrial ovarian and clear cell carcinoma, most likely resulting from accelerated proliferation of endometrial glands and stroma outside of the uterine cavity (Kobayashi et al., 2009; Felix et al., 2010). The TP53 tumor suppressor gene contains a high frequency of missense mutations that are primarily found in the central DNA-binding domain that can alter gene regulation and protein levels and affect cell growth, DNA repair, and apoptosis and promote carcinogenesis (Thomas et al., 1999).

In this study, we investigated the prevalence of the codon 72 TP53 polymorphism and its association with endometriosis risk in a Mexican population. A significant difference in the distribution of the codon 72 Pro/Pro and Pro/Pro-Arg/Pro genotypes was observed between endometriosis patients and healthy women $(\mathrm{OR}=3.3,95 \% \mathrm{CI}=1.7-6.4 ; \mathrm{P}=0.0001$ and $\mathrm{OR}$ $=2.0,95 \% \mathrm{CI}=1.3-3.2 ; \mathrm{P}=0.0007$, respectively). This association was clearly evident in patients with pro/pro-arg/pro genotypes who had stage III-IV endometriosis $(\mathrm{OR}=1.9,95 \% \mathrm{CI}=$ $0.9-3.9 ; \mathrm{P}=0.049$ ). The association between TP53 gene polymorphisms and endometriosis is controversial; some studies report a negative association between endometriosis risk and the TP53 codon 72 polymorphism. These studies suggest that this negative association is influenced by ethnical differences (Shiverick and Salafia, 1999). Other studies suggest an increased risk of endometriosis in patients with the TP53 codon 72 polymorphism (Chang et al., 2002; Hsieh and Lin, 2006; Ribeiro et al., 2009; Ghasemi et al., 2010). Our results indicate that there is a positive correlation between the codon 72 TP53 polymorphism and endometriosis; this correlation is even evident in patients with advanced stage (III or IV) endometriosis. The proline allele of codon 72 polymorphism might affect mRNA splicing and affect gene expression and DNA-protein interactions. This might cause alterations in the endometrial tissue, and when coupled with oxidative stress, may play a central role in the inflammatory reaction of endometriosis. Kobayashi et al. (2009) suggested that the accumulation of pro-oxidant factors such as the heme group and iron present in retrograde menstruation and ovarian hemorrhage can result in toxicity and potentially contribute to endometriosis and the subsequent malignant transformation.

With regard to the association of tobacco consumption in passive smokers and the presence of endometriosis, the World Association for Health suggests that tobacco smoking increased the risk for several diseases such as cancer, spontaneous abortions, infertility, and endometriosis. Several studies have reported a high incidence of spontaneous abortions and infertility in passive smokers (Shiverick et al., 1999; Peppone et al., 2009). Our data corroborate these findings. Tobacco smoke likely has harmful effects on the ovaries, uterus, and endometrium; these effects might be dose-dependent and prolonged exposure may affect implantation and embryo development. Nicotine has been shown to have an anti-estrogenic effect, and 
cadmium and polycyclic aromatic hydrocarbons have been reported to affect estrogen synthesis and metabolism, oocyte formation, and granulosa luteal function (Shiverick et al., 1999).

In conclusion, our results suggest that the frequencies of TP53 codon 72 Pro/Pro and Arg/Pro genotypes are significantly different between control women and endometriosis patients. The differences were clearly evident in stage III-IV endometriosis patients. Taken together, these data indicate that the proline allele of codon 72 TP53 polymorphism might be a good marker for endometriosis patients in the Mexican population. Further studies are warranted to confirm this possibility.

\section{REFERENCES}

Akahane T, Sekizawa A, Purwosunu Y, Nagatsuka M, et al. (2007). The role of p53 mutation in the carcinomas arising from endometriosis. Int. J. Gynecol. Pathol. 26: 345-351.

Ammendola M, Gloria-Bottini F, Sesti F, Piccione E, et al. (2008). Association of p53 codon 72 polymorphism with endometriosis. Fertil. Steril. 90: 406-408.

Ayala YR and Mota GM (2007). Endometriosis: physiopathology and investigation trends (first part). Ginecol. Obstet. Mex. 75: 477-483.

Chang CC, Hsieh YY, Tsai FJ, Tsai CH, et al. (2002). The proline form of p53 codon 72 polymorphism is associated with endometriosis. Fertil. Steril. 77: 43-45.

Chiurillo MA, Moran Y, Cañas M and Valero G (2010). Distribución del polimorfismo codon 72 de TP53 en Venezuela: implicaciones étnicas y Geográficas. Interciencia 35: 202-206.

Doosti A, Zamani M, Ghasemi P, Taherin S, et al. (2011). Association of the p53 codon 72 polymorphism with colorectal cancer in South West of Iran. Sci. Res. Essays 6: 3148-3152.

Dunselman G (2002). Endometriosis. Patogenia de los Implantes Endometriósicos. In: Reproducción Humana (Pellicer A and Simón C, eds.). Mc GrawHill, España, 191-197.

Felix A, Nogales FF and Arias-Stella J (2010). Polypoid endometriosis of the uterine cervix with Arias-Stella reaction in a patient taking phytoestrogens. Int. J. Gynecol. Pathol. 29: 185-188.

Ghasemi N, Karimi-Zarchi M, Mortazavi-Zadeh MR and Atash-Afza A (2010). Evaluation of the frequency of TP53 gene codon 72 polymorphisms in Iranian patients with endometrial cancer. Cancer Genet. Cytogenet. 196: 167-170.

Giudice LC and Kao LC (2004). Endometriosis. Lancet 364: 1789-1799.

Goodman C, Jeyendran RS and Coulam CB (2009). P53 tumor suppressor factor, plasminogen activator inhibitor, and vascular endothelial growth factor gene polymorphisms and recurrent implantation failure. Fertil. Steril. 92: 494-498.

Gruppo Italiano per lo Studio dell'Endometriosi (2001). Relationship between stage, site and morphological characteristics of pelvic endometriosis and pain. Hum. Reprod. 16: 2668-2671.

Gylfason JT, Kristjansson KA, Sverrisdottir G, Jonsdottir K, et al. (2010). Pelvic endometriosis diagnosed in an entire nation over 20 years. Am. J. Epidemiol. 172: 237-243.

Hsieh YY and Lin CS (2006). P53 codon 11, 72, and 248 gene polymorphisms in endometriosis. Int. J. Biol. Sci. 2: 188193.

Kang HJ, Feng Z, Sun Y, Atwal G, et al. (2009). Single-nucleotide polymorphisms in the p53 pathway regulate fertility in humans. Proc. Natl. Acad. Sci. U. S. A. 106: 9761-9766.

Kern SE, Kinzler KW, Bruskin A, Jarosz D, et al. (1991). Identification of p53 as a sequence-specific DNA-binding protein. Science 252: 1708-1711.

Kobayashi H, Kajiwara H, Kanayama S, Yamada Y, et al. (2009). Molecular pathogenesis of endometriosis-associated clear cell carcinoma of the ovary (review). Oncol. Rep. 22: 233-240.

Liu G, Miller DP, Zhou W, Thurston SW, et al. (2001). Differential association of the codon 72 p53 and GSTM1 polymorphisms on histological subtype of non-small cell lung carcinoma. Cancer Res. 61: 8718-8722.

Mandai M, Yamaguchi K, Matsumura N, Baba T, et al. (2009). Ovarian cancer in endometriosis: molecular biology, pathology, and clinical management. Int. J. Clin. Oncol. 14: 383-391.

Miller SA, Dykes DD and Polesky HF (1988). A simple salting out procedure for extracting DNA from human nucleated cells. Nucleic Acids Res. 16: 1215.

Nouri K, Ott J, Krupitz B, Huber JC, et al. (2010). Family incidence of endometriosis in first-, second-, and third-degree relatives: case-control study. Reprod. Biol. Endocrinol. 8: 85.

Peppone LJ, Piazza KM, Mahoney MC, Morrow GR, et al. (2009). Associations between adult and childhood secondhand 
smoke exposures and fecundity and fetal loss among women who visited a cancer hospital. Tob. Control 18: 115-120. Ribeiro Junior CL, Arruda JT, Silva CT and Moura KK (2009). Analysis of p53 codon 72 gene polymorphism in Brazilian patients with endometriosis. Genet. Mol. Res. 8: 494-499.

Sanguinetti CJ, Dias NE and Simpson AJ (1994). Rapid silver staining and recovery of PCR products separated on polyacrylamide gels. Biotechniques 17: 914-921.

Shiverick KT and Salafia C (1999). Cigarette smoking and pregnancy I: ovarian, uterine and placental effects. Placenta 20: 265-272.

Själander A, Birgander R, Saha N, Beckman L, et al. (1996). p53 polymorphisms and haplotypes show distinct differences between major ethnic groups. Hum. Hered. 46: 41-48.

Suárez-Rincon AE, Moran-Moguel MC, Montoya-Fuentes H, Gallegos-Arreola MP, et al. (2002). Polymorphism in codon 72 of the p53 gene and cervico-uterine cancer risk in Mexico. Ginecol. Obstet. Mex. 70: 344-348.

Sunderam S, Chang J, Flowers L, Kulkarni A, et al. (2009). Assisted reproductive technology surveillance-United States, 2006. MMWR Surveill Summ. 58: 1-25.

Thomas M, Kalita A, Labrecque S, Pim D, et al. (1999). Two polymorphic variants of wild-type p53 differ biochemically and biologically. Mol. Cell Biol. 19: 1092-1100.

Troyer MR (2007). Differential diagnosis of endometriosis in a young adult woman with nonspecific low back pain. Phys. Ther. 87: 801-810. 